\title{
Does rumination mediate the effect of depressive symptoms on cigarette dependence and craving in seeking treatment smokers?
}

Carmela Martínez-Vispo, PhD. ${ }^{1 *}$, Carmen Senra, $\mathrm{PhD}^{2}$, Ana López-Durán, $\mathrm{PhD}^{1,2}$, Elena Fernández del Río, $\mathrm{PhD}^{3}$, \& Elisardo Becoña, $\mathrm{PhD}^{1,2}$

${ }^{1}$ Smoking Cessation and Addictive Disorders Unit, Department of Clinical Psychology and Psychobiology, Faculty of Psychology, University of Santiago de Compostela, Galicia, Spain

${ }^{2}$ Department of Clinical Psychology and Psychobiology, Faculty of Psychology, University of Santiago de Compostela, Galicia, Spain

${ }^{3}$ Department of Psychology and Sociology, University of Zaragoza, Zaragoza, Spain

Running head: Rumination, depression, cigarette dependence and withdrawal symptoms

\section{Corresponding author:}

Carmela Martínez Vispo, PhD.

ORCID: 0000-0002-8503-1791

Smoking and Addictive Disorders Unit. University of Santiago de Compostela. Faculty of Psychology. Department of Clinical Psychology and Psychobiology. Campus Vida. 15782 Santiago de Compostela, Spain. Telf. no.: (0034) 881813939.

E-mail address: carmela.martinez@usc.es

\section{Additional authors information}

Carmen Senra, ORCID: 0000-0001-5980-6680

Ana López-Durán, ORCID: 0000-0001-7661-8972

Elena Fernández del Río, ORCID: 0000-0002-9645-8109

Elisardo Becoña, ORCID: 0000-0002-6639-3834 


\begin{abstract}
Despite the advances in understanding the relationship between smoking and depressive symptomatology, scarce research has investigated cognitive variables underlying in such relation. The main aim of this study is to examine the mediating effect of two rumination subtypes (brooding and reflection) in the link between depressive symptoms and both cigarette dependence level and tobacco craving in treatment-seeking smokers. Participants were 275 adult daily smokers seeking treatment to quit smoking $(61.5 \%$ females; Mage $=45.3$ years; $\mathrm{SD}=10.9$ ). Multiple mediation analysis was conducted to explore the mediating effects of rumination (brooding and reflection) in the relation between depressive symptoms, cigarette dependence level, and craving. Results showed a significant indirect effect of depressive symptoms through the joint of both rumination subtypes on cigarette dependence $(\beta=0.089 ; 95 \%$ BootCI $[0.006,0.168])$, and craving $(\beta$ $=0.123 ; 95 \%$ BootCI $[0.048,0.205])$. The specific analysis of each mediator showed that only brooding subtype had a significant effect on the relation between depressive symptoms and tobacco craving $(\beta=$ 0.101; 95\% BootCI [0.023, 0.186]). Findings of the present study provide further evidence for the role of rumination in smoking-related variables and for the potential value of introducing rumination-focused interventions into smoking-cessation interventions.
\end{abstract}

\title{
Keywords
}

Depressive symptoms; rumination; cigarette dependence; tobacco craving 


\section{Introduction}

The relationship between smoking and depression has been widely demonstrated both crosssectionally (Lineberry, Allen, Nash, \& Galardy, 2009; Weinberger et al., 2016) and longitudinally (Bakhshaie, Zvolensky, \& Goodwin, 2015; Tjora et al., 2014). Several authors have informed that a high percentage of smokers suffer from depressive symptoms compared with individuals who have never smoked and those who had quit smoking (Flensborg-Madsen et al., 2011; Hitsman et al., 2013). It is also known that smokers with depressive symptoms report higher rates of cigarette dependence, higher tobacco cravings, and greater difficulty to quit smoking (Cooper, Borland, Yong, \& Fotuhi, 2016; Covey, Glassman, \& Stetner, 1990; Weinberger, Pilver, Desai, Mazure, \& McKee, 2013).

Cigarette dependence is a complex phenomenon that involves nicotine-pharmacological effects, the habit itself and smoking-related conditioning, as well as associated psychosocial functions (Fagerstrom, 2012). In the case of smokers with depressive symptoms, smoking behavior is strengthened due to the expectation that tobacco alleviates depressive distress. Therefore, smokers with depressive symptomatology have less probability of achieving abstinence and maintaining it at short (Hitsman et al., 2013) and long term (Brodbeck, Bachmann, Brown, \& Znoj, 2014).

Another relevant feature of tobacco addiction is craving (Sayette, 2016; Skinner \& Aubin, 2010). This construct has been defined as the subjective experience of desire, urge, or intense need to use a substance or engage in a behavior, which is usually described as an overwhelming feeling of loss of control over behavior (Ferguson \& Shiffman, 2013). Research has shown that this experience is related to smoking persistence and relapse (Wray, Gass, \& Tiffany, 2013) and that it can be elicited in non-deprived smokers (Hogarth, Dickinson, \& Duka, 2010) and even in quitters who have maintained abstinence over a period of six to twelve months (Ussher, Beard, Abikoye, Hajek, \& West, 2013). Research conducted with smokers experiencing depressive symptoms has found that they tend to report higher intensity of tobacco craving compared to smokers without such symptomatology (Pomerleau et al., 2005; Weinberger, George, \& McKee, 2011).

Recent smoking-related studies have identified some changes in smokers seeking smokingcessation treatment (Becoña, López-Durán, Fernández del Río, \& Martínez, 2014; Leyro et al., 2016). Specifically, research has shown that cigarette consumption (i.e., number of cigarettes smoked per day) has decreased, but cigarette dependence (i.e., assessed with the Fagerström Test for Nicotine Dependence) remains unchanged. Moreover, a relevant finding of these studies is that the presence of depressive symptoms has increased in smokers seeking smoking-cessation treatment. Consequently, examining in greater depth the relationship between depressive symptoms and specific smoking-related variables could provide new insights at the theoretical level and also at a practical level to refine the treatments.

A promising perspective to advance in the analysis of the relationship between depressive symptoms and smoking could be to consider the different response styles that individuals use to cope with unpleasant feelings. A coping strategy characteristically related to depressive symptoms, which is also relevant in substance use, is rumination (du Pont, Rhee, Corley, Hewitt, \& Friedman, 2018; Nolen-Hoeksema \& 
Watkins, 2011). Rumination consists of a passive repetitive response to a depressive or dysphoric state related to past failures or errors (Nolen-Hoeksema, 2008). Although rumination is generally used as an emotional regulation strategy by which individuals try to achieve more insight on depressed mood, it has the opposite effect because the vicious circle of negative thoughts worsen the distress, lengthening the depressive episode and reducing the effectiveness of the solution of the problems (Brinker \& Dozois, 2009; Nolen-Hoeksema, Wisco, \& Lyubomirsky, 2008). Rumination causes this effect because individuals focus their attention on their depressed emotional state instead of diverting attention to external stimuli distracting from their psychological distress (Just \& Alloy, 1997; Nolen-Hoeksema, 1991). The identification of two subtypes of rumination -brooding and reflection- was an important step in the understanding of this construct (Treynor, Gonzalez, \& Nolen-Hoeksema, 2003). According to these authors, brooding alludes to the passive and cyclical focus on negative emotions, whereas reflection refers to emotionally neutral pondering. While the association between the brooding component of rumination and depressive symptoms has been widely documented, both in clinical (Merino, Senra, \& Ferreiro, 2016) and nonclinical samples (Olson \& Kwon, 2008; Senra, Merino, \& Ferreiro, 2018), the role of the reflection component remains uncertain (Burwell \& Shirk, 2007; Harris, Pepper, \& Maack, 2008).

Previous research illustrates the relationship between rumination and health risk behaviors. For instance, rumination has been shown to have a significant effect on increasing craving in alcohol-dependent drinkers (Caselli et al., 2013), and has also been found to be a significant predictor of substance use problems in adolescence (Willem, Bijttebier, Claes, \& Raes, 2011). In fact, a recent meta-analysis has concluded that cognitive perseveration, characteristic of rumination, is associated with different health risk behaviors, such as smoking (Clancy, Prestwich, Caperon, \& O'Connor, 2016). The studies mentioned above highlight that the excessive and continuous self-focus that ruminative thoughts arouse amplifies the state of dysphoria, which promotes the use of substances in order to cope and/or escape from this emotional distress (Ingram, 1990). In this vein, Richmond and colleagues (Richmond, Spring, Sommerfeld, \& McChargue, 2001) found that rumination is more strongly correlated with depressive symptoms among smokers than among non-smokers. Another cross-sectional study suggested that higher level rumination was associated with greater number of lifetime failed quit smoking attempts (Dvorak, Simons, \& Wray, 2011).

Overall, previous publications have supported the relationship between depressive symptoms and smoking and between rumination and health risk behaviors; however, the relationship between these variables has been largely unexplored. Particularly, it is unknown the role of rumination on how depressive symptoms affect the level of dependence and craving in smokers seeking smoking-cessation treatment. In order to overcome this gap, the aim of this study was to examine the potential mediating effect of rumination (brooding and reflection) in the link between depressive symptoms and: (1) cigarette dependence level and, and (2) craving. In accordance with these objectives and with the results reported in the literature, we hypothesize that rumination will significantly mediate the relationship between depressive symptoms and tobacco dependence level, and craving in particular, the subtype brooding of rumination. 


\section{Method}

\subsection{Participants}

The sample consisted of 275 smokers seeking smoking-cessation treatment at XXX. The inclusion criteria were: (1) aged 18 or over; (2) providing written informed consent; (3) wishing to participate in the study; and (4) smoking at least 8 cigarettes per day. Of the total sample, $62.7 \%$ were female, and the average age was 45.3 years $(S D=10.9$, range $=19-73)$. Regarding marital status, $50.9 \%$ of the participants were married, $29.8 \%$ were single, $14.2 \%$ were separated or divorced, and $4 \%$ were widowed. In terms of educational level, $21.5 \%$ had a primary level of education (less than High School), 38.2\% had a secondary level of education (High School or General Education Diploma), and 40.4\% had a high level of education (College or Technical School). The sample was entirely composed of Caucasian individuals. Regarding smoking-related variables, participants smoked a daily average of 19.1 cigarettes $(S D=7.3)$ and had smoked for almost 26 years $(M=26.4, S D=11.4)$.

\subsection{Measures}

Beck Depression Inventory II (BDI-II; (Beck, Steer, \& Brown, 1996)). It is a 21-item self-report scale measuring current depressive symptomatology over the last two weeks. The total score ranges from 0 to 63 , with higher scores indicating higher depressive symptoms. We used the Spanish version (Sanz, Perdigón, \& Vázquez, 2003), which has appropriate psychometric characteristics. In this sample Cronbach's alpha was 0.90 .

Ruminative Response Scale (RRS; (Nolen-Hoeksema, 1991)). It consists on a 22-item self-report for assessing ruminative coping responses. Treynor et al. (2003) found that 12 items from the RRS overlapped with depressive symptoms, so the resulting 10-item version was used. The instrument has two factors: Brooding (5 items) and Reflection (5 items). The Spanish version of the RRS, which has adequate psychometric properties (Hervás Torres, 2008), was used. In this sample Cronbach's alpha scores for Brooding and Reflection were 0.79 and 0.77 , respectively.

Fagerström Test of Cigarette Dependence (FTCD; Heatherton et al. 1991). This scale is made up of six items for the assessment of cigarette dependence, yielding a total score between $0-10$. This instrument has shown strong relations with other smoking-related variables (Heatherton et al., 1991), and it is the most widely used instrument for rating cigarette dependence. The Spanish version (Becoña \& Vázquez, 1998), which has been shown to have adequate psychometric quality was used. Cronbach's alpha in this sample was 0.61 .

Minnesota Nicotine Withdrawal Scale (MNWS; Hughes and Hatsukami 1986). It consists of eight items measuring tobacco withdrawal symptoms (item value ranging from 0 to 4 ), including craving to smoke. For the purpose of this study, we only used the Item 8, which refers specifically to tobacco craving. We used the Spanish translation of the scale used in this study (Piñeiro, López-Durán, Martínez, Brandon, \& Becoña, 2014). In this sample the Cronbach's alpha was 0.84 for the total scale, and 0.81 when removing the mood-related item. 


\subsection{Procedure}

Participants were recruited from the community to participate in a randomized controlled trial (RCT) between January 2016 and April 2017 (clinicaltrials.gov\#XXX). Following a preliminary telephone contact, if interested, participants attended a first eligibility and baseline assessment session. All participants provided written informed consent prior to study initiation, and the study was approved by the Bioethics Committee of the University of XXX. The current study is based on secondary analysis of baseline data of the previously mentioned RCT (XXX).

\subsection{Analytic strategy}

Descriptive statistics and Pearson correlations were conducted. Multiple mediation analyses were performed with the PROCESS macro for SPSS (Hayes \& Little, 2018). Two multiple mediation models were tested in which depressive symptoms were the independent variable, the subtypes of rumination (brooding and reflection) were potential mediators, and cigarette dependence level and craving, respectively, were the dependent variables. All study variables were introduced in the model as continuous based on scores obtained in the questionnaires above described. Gender and age were controlled in these analyses. Bias-corrected bootstrapping (with 20,000 resamples) was used to generate confidence intervals for the hypotheses tested because it is the preferred method for assessing indirect effects both in simple (MacKinnon, Fairchild, \& Fritz, 2007) and multiple mediator models (Preacher \& Hayes, 2008). In addition, pairwise contrasts of all the specific indirect effects involved in each model were also calculated. Results are presented as standardized coefficients for direct and indirect effects (Preacher \& Kelley, 2011).

Finally, reverse models were conducted for each outcome variable, in which the proposed mediator and predictor variables were reversed. This methodological approach has been recommended when using cross-sectional data in order to evaluate the specificity of the hypothesized models (Preacher \& Hayes, 2008).

\section{Results}

\subsection{Preliminary Analyses}

Descriptive statistics and Pearson correlations of the study variables are presented in Table 1. Depressive symptoms were significantly correlated with the proposed mediating variables (brooding and reflection) and with the two outcome variables (cigarette dependence and craving). According to Steiger's $z$-tests, depressive symptoms were similarly related to craving and to $\operatorname{FTCD}(z=0.364, p=.715)$.

\subsection{Multiple Mediation Analyses}

Regarding the analyses for cigarette dependence (FTCD scores), both the total effect model $\left(R^{2}=\right.$ $.073 ; F(3,271)=7.170, p<.001)$ and the full model $\left(R^{2}=.096 ; F(5,269)=5.761, p<.001\right)$ were statistically significant. In particular, the analysis showed that the direct effect of depressive symptoms on cigarette dependence was significant ( $\beta=0.251 ; 95 \%$ BootCI $[0.032,0.086])$ as the bias-corrected $95 \%$ 
confidence interval for the total indirect effect did not contain zero (Table 2). The total indirect effect of depressive symptoms through the two proposed mediators was also significant $(\beta=0.089 ; 95 \%$ BootCI $[0.006,0.168])$. When examining the specific indirect effect of each mediator (Figure 1), the pairwise contrasts showed that the specific indirect effects of brooding and reflection were not significantly different from each other $(\beta=0.037 ; 95 \%$ BootCI $[-0.090,0.155])$.

Results of the analyses concerning craving showed that the total effect $\left(R^{2}=.241 ; \mathrm{F}(3,271)=\right.$ $5.609, p<.001)$ and full models $\left(R^{2}=.310 ; F(5,269)=5.720, p<.001\right)$ were significant. The total indirect effect of the two proposed mediators was also significant $(\beta=0.123 ; 95 \%$ BootCI $[0.048,0.205])$. When analyzing the specific indirect effect of each rumination subtype, only brooding $(\beta=0.101 ; \mathrm{SE}=0.041$, 95\% BootCI [0.023, 0.186]) was significant (Table 2 and Figure 2).

\subsection{Reverse Models}

A series of reverse models were conducted examining whether depression symptomatology could mediate in the relation between rumination subtypes and the proposed smoking-related variables (cigarette dependence and craving). The two models including reflection as the predictor showed a nonsignificant indirect effect via depressive symptoms on cigarette dependence $(\beta=-0.006,95 \%$ BootCI [-0.033, 0.019]; and on carving $(\beta=-0.003,95 \%$ BootCI $[-0.021,0.10]$. When examining models including brooding as the predictor, results showed a nonsignificant indirect effect through depression on the relation with craving, but a significant indirect effect on cigarette dependence $(\beta=0.096,95 \%$ BootCI [0.010, 0.194].

\section{Discussion}

This study was designed to investigate the potential mediating role of rumination (brooding and reflection) in the relationship between depressive symptoms and cigarette dependence level and craving in a community sample of adults seeking smoking-cessation treatment.

In a preliminary step, we found that depressive symptoms were significantly and positively correlated to cigarette dependence level and tobacco craving. Our findings are in agreement with studies indicating that smokers with higher depressive symptoms also report higher craving and higher rates of cigarette dependence (Cooper, Borland, McKee, Yong, \& Dugué, 2016; Weinberger et al., 2013; Ziedonis et al., 2008). This could be due to the fact that smokers with greater depressive symptomatology experience a negative internal state that they may try to avoid or escape through smoking, which could strengthen the rewarding value of smoking (Clancy et al., 2016; Mathew, Hogarth, Leventhal, Cook, \& Hitsman, 2017).

Regarding the first aim of the study, we found that the joint effect of the two subtypes of rumination significantly mediated the relationship between depressive symptoms and cigarette dependence level. However, neither of them separately reached statistical significance. This result suggests that, independently of the adaptive quality of the rumination subtype, it is the perseverative cognitive process that captures the smoker in cigarette dependence. Therefore, our first hypothesis is only partially confirmed, although this finding is in consonance with previous research examining the relation between rumination 
and substance use severity and dependence (Adrian, McCarty, King, McCauley, \& Stoep, 2014; Memedovic et al., 2019).

In relation to the second aim, the results of the mediation analyses showed that the total indirect effect of both subtypes of rumination explained a significant proportion of the association between depressive symptoms and tobacco craving. The examination of the particular contribution of each mediator revealed that only the brooding subtype was a significant mediating pathway. This finding is in line with metacognition models such as that proposed by Spada, Caselli, and Wells (2013), who suggest that addictive behaviors could be considered as coping strategies to control unwanted thinking and negative emotional states. Previous studies, in consonance with this model, have shown that rumination is related to an intensification of cravings and negative affect, which boost negative beliefs about the need to control thoughts enhancing the likelihood of substance use (Bravo et al., 2018; Caselli et al., 2013; Hamonniere \& Varescon, 2018).

Our findings, in line with other studies (Richmond et al., 2001), support the argument that some smokers respond to their depressive discomfort with a ruminative coping strategy in an attempt to gain control over adverse events or internal states. However, the ruminative process does not relieve emotional distress but rather amplifies and maintains it. Therefore, it is plausible to assume that some smokers will try to escape from this aversive state by smoking, due to the damping effect of cigarettes on distress, which contributes to increased tobacco dependence and craving.

Additionally, our results also showed that brooding was the rumination subtype most strongly related to tobacco dependence and craving. This is congruent with the consideration of the brooding subtype as a maladaptive coping strategy characterized by the negative nature of thought-related self-evaluation, self-criticism, and self-judgment (Watkins, 2008). Moreover, the results of the reverse models suggested that, at least with regard to cigarette dependence level, the relation between the brooding rumination subtype and depressive symptoms may be reciprocal. This is in line with recent research showing that rumination, as an unifactorial construct, and depressive symptoms have a bidirectional relationship, constituting a potential risk factor and a consequence of each other (Whisman, du Pont, \& Butterworth, 2020).

Overall, our results suggest that smokers who respond to their depressive discomfort with ruminative coping, with the intention of relieving their distress (Nolen-Hoeksema \& Watkins, 2011), experience a higher level of cigarette dependence and craving. Therefore, in terms of clinical implications, this study suggests that rumination may act as a cognitive pathway through which depressive symptoms lead to a great intensity of cigarette dependence and tobacco craving. These relationships could impact on smoking cessation outcomes, as cigarette dependence and craving are considered barriers to achieve abstinence (Breslau \& Johnson, 2000; Mathew et al., 2017; Sayette, 2016). In fact, craving and negativerelated mood relief through smoking reinforces continued smoking, increasing the likelihood of not achieving smoking abstinence or increasing the risk of relapse (Frandsen, Thorpe, Shiffman, \& Ferguson, 2017), a process which could be impacted by the presence of rumination, although this possibility is speculative and cannot be verified. Cognitive treatment approaches that have been shown to be effective in 
correcting and modifying this spiral of repetitive negative thoughts (Querstret \& Cropley, 2013) seem particularly promising to be included as part of smoking cessation interventions. Specifically, smokingcessation treatments could consider the negative self-referential state of the ruminative thoughts of smokers with depressive symptomatology. Thus, given that rumination is defined by high levels of abstraction, could be beneficial to stimulate particular emotional memories that foster adequate emotional processing (Watkins, 2008), and to train smokers in focusing their attention to the present and to specific rather than abstract issues (Segal, Williams, \& Teasdale, 2013).

Several limitations of the study should be noted. First, the cross-sectional design of the study does not allow any inference about the direction of the effects. Nevertheless, we attempted to improve confidence in the proposed models by evaluating alternative ones, in which we reversed the predictor and mediator variables. Second, only self-report measures were used, and although these instruments may be appropriate for reflecting participants' direct perceptions, they can introduce some biases in the results. Related to this, craving assessment consisted of a single item, and although research has stated that this type of assessment is reliable and clinically useful (Tiffany \& Wray, 2012), future studies should confirm the pattern of results found using multi-item and multidimensional measurements of tobacco craving. Third, the sample used in this study was comprised of non-clinically depressed smokers, and therefore, the magnitude of the effect of rumination on the relation between depression and tobacco dependence and craving may be minimized. Examination of the role of rumination in clinically depressed smokers is necessary to elucidate the robustness of the results found. Lastly, the use of a sample of smokers seeking treatment to quit smoking prevents generalization of the results to smokers from the general population. It would be of interest to test whether the mediating effect of rumination also occurs in a sample of smokers who are not seeking smoking-cessation treatment.

In conclusion, rumination could be a relevant variable to partially explain the relation between depressive symptoms and cigarette dependence level as well as craving in a sample of treatment-seeking smokers with a broad range of depressive symptoms. These findings provide further evidence for the role of rumination, and concretely brooding subtype, in smoking-related variables and for the potential value of introducing rumination-focused interventions into smoking cessation interventions. 


\section{Compliance with Ethical Standards}

\section{Ethical Approval}

All procedures performed involving human participants were in accordance with the ethical standards of the Bioethics Committee of the University of XXX, and with the 1964 Helsinki declaration and its later amendments or comparable ethical standards. This article does not contain any studies with animals performed by any of the authors.

\section{Informed consent}

Informed consent was obtained from all individual participants included in the study.

\section{Conflicts of interest}

All authors declare that they have no conflicts of interest.

\section{Funding}

This research was supported by the Spanish Ministry of Economy and Competiveness (Project reference: PSI2015-66755-R) and co-financed by FEDER (European Regional Development Fund; pluri-annual plan 2014-2020).

\section{Role of the Funding Source}

Spanish Ministry of Economy and Competiveness (Ministerio de Economía y Competitividad) and FEDER had no role in the study design, collection, analysis or interpretation of the data, writing the manuscript, or the decision to submit the paper for publication.

\section{Contributors}

All authors were substantially involved in the conception of the study and participated in its design. CMV, ALD, and EB collected the data. CS and CMV conducted the statistical analysis. CMV and CS drafted the first version of the manuscript with the assistance of ALD, EFR and EB. All authors contributed to the review and editing of the manuscript and have read and approved the final manuscript. 


\section{References}

Adrian, M., McCarty, C., King, K., McCauley, E., \& Stoep, A. Vander. (2014). The internalizing pathway to adolescent substance use disorders: Mediation by ruminative reflection and ruminative brooding. Journal of Adolescence, 37(7), 983-991. doi: 10.1016/j.adolescence.2014.07.010

Bakhshaie, J., Zvolensky, M. J., \& Goodwin, R. D. (2015). Cigarette smoking and the onset and persistence of depression among adults in the United States: 1994-2005. Comprehensive Psychiatry, 60, 142-148. doi: 10.1016/j.comppsych.2014.10.012

Beck, A., Steer, R., \& Brown, G. (1996). Beck Depression Inventory-second edition. Manual. (Texas). San Antonio: The Psychological Corporation.

Becoña, E., López-Durán, A., Fernández del Río, E., \& Martínez, Ú. (2014). Changes in the profiles of smokers seeking cessation treatment and in its effectiveness in Galicia (Spain) 2001-10. BMC Public Health, 14(1), 613. doi: 10.1186/1471-2458-14-613

Becoña, E., \& Vázquez, F. L. (1998). The Fagerström Test for Nicotine Dependence in a Spanish sample. Psychological Reports, 83(3_suppl), 1455-1458. doi: 10.2466/pr0.1998.83.3f.1455

Bravo, A. J., Pilatti, A., Pearson, M. R., Mezquita, L., Ibáñez, M. I., \& Ortet, G. (2018). Depressive symptoms, ruminative thinking, drinking motives, and alcohol outcomes: A multiple mediation model among college students in three countries. Addictive Behaviors, 76, 319-327. doi: 10.1016/j.addbeh.2017.08.028

Breslau, N., \& Johnson, E. O. (2000). Predicting smoking cessation and major depression in nicotinedependent smokers. American Journal of Public Health, 90(7), 1122-1127.

Brinker, J. K., \& Dozois, D. J. A. (2009). Ruminative thought style and depressed mood. Journal of Clinical Psychology, 65(1), 1-19. doi: 10.1002/jclp.20542

Brodbeck, J., Bachmann, M. S., Brown, A., \& Znoj, H. J. (2014). Effects of depressive symptoms on antecedents of lapses during a smoking cessation attempt: An ecological momentary assessment study. Addiction, 109(8), 1363-1370. doi: 10.1111/add.12563

Burwell, R. A., \& Shirk, S. R. (2007). Subtypes of rumination in adolescence: associations between brooding, reflection, depressive symptoms, and coping. Journal of Clinical Child \& Adolescent Psychology, 36(1), 56-65. doi: 10.1080/15374410709336568

Caselli, G., Gemelli, A., Querci, S., Lugli, A. M., Canfora, F., Annovi, C., ... Watkins, E. R. (2013). The effect of rumination on craving across the continuum of drinking behaviour. Addictive Behaviors, 38(12), 2879-2883. doi: 10.1016/j.addbeh.2013.08.023

Clancy, F., Prestwich, A., Caperon, L., \& O’Connor, D. B. (2016). Perseverative Cognition and Health Behaviors: A Systematic Review and Meta-Analysis. Frontiers in Human Neuroscience, 10, 534. doi: 10.3389/fnhum.2016.00534 
Cooper, J., Borland, R., McKee, S. A., Yong, H.-H., \& Dugué, P.-A. (2016). Depression motivates quit attempts but predicts relapse: differential findings for gender from the International Tobacco Control Study. Addiction, 111(8), 1438-1447. doi: 10.1111/add.13290

Cooper, J., Borland, R., Yong, H.-H., \& Fotuhi, O. (2016). The impact of quitting smoking on depressive symptoms: findings from the International Tobacco Control Four-Country Survey. Addiction, 111(8), 1448-1456. doi: 10.1111/add.13367

Covey, L. S., Glassman, A. H., \& Stetner, F. (1990). Depression and depressive symptoms in smoking cessation. Comprehensive Psychiatry, 31(4), 350-354. doi: 10.1016/0010-440X(90)90042-Q

du Pont, A., Rhee, S. H., Corley, R. P., Hewitt, J. K., \& Friedman, N. P. (2018). Rumination and Psychopathology: Are Anger and Depressive Rumination Differentially Associated With Internalizing and Externalizing Psychopathology? Clinical Psychological Science, 6(1), 18-31. doi: $10.1177 / 2167702617720747$

Dvorak, R., Simons, J., \& Wray, T. (2011). Impulsivity moderates the association between depressive rumination and number of quit attempt failures by smokers. Addiction Research \& Theory, 19(3), 283-288. doi: 10.3109/16066359.2010.512110

Fagerstrom, K. (2012). Determinants of tobacco use and renaming the FTND to the Fagerstrom Test for Cigarette Dependence. Nicotine \& Tobacco Research, 14(1), 75-78. doi: 10.1093/ntr/ntr137

Ferguson, S. G., \& Shiffman, S. (2013). Relation of craving and appetitive behavior. In P. M. Millier (Ed.), Principles of addiction (pp. 473-479). San Diego: Academic Press.

Flensborg-Madsen, T., von Scholten, M. B., Flachs, E. M., Mortensen, E. L., Prescott, E., \& Tolstrup, J. S. (2011). Tobacco smoking as a risk factor for depression. A 26-year population-based follow-up study. Journal of Psychiatric Research, 45(2), 143-149. doi: 10.1016/j.jpsychires.2010.06.006

Frandsen, M., Thorpe, M., Shiffman, S., \& Ferguson, S. G. (2017). A Clinical Overview of Nicotine Dependence and Withdrawal. In Negative Affective States and Cognitive Impairments in Nicotine Dependence (pp. 205-215). doi: 10.1016/B978-0-12-802574-1.00012-0

Hamonniere, T., \& Varescon, I. (2018). Metacognitive beliefs in addictive behaviours: A systematic review. Addictive Behaviors, 85, 51-63. doi: 10.1016/j.addbeh.2018.05.018

Harris, P. W., Pepper, C. M., \& Maack, D. J. (2008). The relationship between maladaptive perfectionism and depressive symptoms: The mediating role of rumination. Personality and Individual Differences, 44(1), 150-160. doi: 10.1016/J.PAID.2007.07.011

Hayes, A. F., \& Little, T. D. (2018). Introduction to mediation, moderation, and conditional process analysis : a regression-based approach (Second Edi). New York: Guilford Press.

Heatherton, T. F., Kozlowski, L. T., Frecker, R. C., \& Fagerström, K. O. (1991). The Fagerström Test for Nicotine Dependence: a revision of the Fagerström Tolerance Questionnaire. British Journal of Addiction, 86(9), 1119-1127. 
Hervás Torres, G. (2008). Adaptación al castellano de un instrumento para evaluar el estilo rumiativo.

Revista de Psicopatología y Psicología Clínica, 13(2), 111-121. doi:

10.5944/rppc.vol.13.num.2.2008.4054

Hitsman, B., Papandonatos, G. D., McChargue, D. E., DeMott, A., Herrera, M. J., Spring, B., ... Niaura, R. (2013). Past major depression and smoking cessation outcome: a systematic review and metaanalysis update. Addiction, 108(2), 294-306. doi: 10.1111/add.12009

Hogarth, L., Dickinson, A., \& Duka, T. (2010). The associative basis of cue-elicited drug taking in humans. Psychopharmacology, 208(3), 337-351. doi: 10.1007/s00213-009-1735-9

Hughes, J. R., \& Hatsukami, D. (1986). Signs and symptoms of tobacco withdrawal. Archives of General Psychiatry, 43(3), 289-294. doi: 10.1001/archpsyc.1986.01800030107013

Ingram, R. E. (1990). Self-focused attention in clinical disorders: Review and a conceptual model. Psychological Bulletin, 107(2), 156-176. doi: 10.1037/0033-2909.107.2.156

Just, N., \& Alloy, L. B. (1997). The response styles theory of depression: tests and an extension of the theory. Journal of Abnormal Psychology, 106(2), 221-229. Retrieved from http://www.ncbi.nlm.nih.gov/pubmed/9131842

Leyro, T. M., Crew, E. E., Bryson, S. W., Lembke, A., Bailey, S. R., Prochaska, J. J., ... David, S. P. (2016). Retrospective analysis of changing characteristics of treatment-seeking smokers: implications for further reducing smoking prevalence. BMJ Open, 6(6), e010960. doi: 10.1136/bmjopen-2015-010960

Lineberry, T. W., Allen, J. D., Nash, J., \& Galardy, C. W. (2009). Population-based prevalence of smoking in psychiatric inpatients: a focus on acute suicide risk and major diagnostic groups. Comprehensive Psychiatry, 50(6), 526-532. doi: 10.1016/J.COMPPSYCH.2009.01.004

MacKinnon, D. P., Fairchild, A. J., \& Fritz, M. S. (2007). Mediation analysis. Annual Review of Psychology, 58, 593-614. doi: 10.1146/annurev.psych.58.110405.085542

Mathew, A. R., Hogarth, L., Leventhal, A. M., Cook, J. W., \& Hitsman, B. (2017). Cigarette smoking and depression comorbidity: systematic review and proposed theoretical model. Addiction, 112(3), 401412. doi: 10.1111/add.13604

Memedovic, S., Slade, T., Ross, J., Darke, S., Mills, K. L., Marel, C., .. Teesson, M. (2019). Rumination and problematic substance use among individuals with a long-term history of illicit drug use. Drug and Alcohol Dependence, 203, 44-50. doi: 10.1016/J.DRUGALCDEP.2019.05.028

Merino, H., Senra, C., \& Ferreiro, F. (2016). Are worry and rumination specific pathways linking neuroticism and symptoms of anxiety and depression in patients with generalized anxiety disorder, major depressive disorder and mixed anxiety-depressive disorder? PLOS ONE, 11(5), e0156169. doi: 10.1371/journal.pone.0156169

Nolen-Hoeksema, S. (1991). Responses to depression and their effects on the duration of depressive 
episodes. Journal of Abnormal Psychology, 100(4), 569-582. doi: 10.1037/0021-843X.100.4.569

Nolen-Hoeksema, S. (2008). The Response Styles Theory. In Depressive Rumination (pp. 105-123). doi: 10.1002/9780470713853.ch6

Nolen-Hoeksema, S., \& Watkins, E. R. (2011). A Heuristic for Developing Transdiagnostic Models of Psychopathology. Perspectives on Psychological Science, 6(6), 589-609. doi: $10.1177 / 1745691611419672$

Nolen-Hoeksema, S., Wisco, B. E., \& Lyubomirsky, S. (2008). Rethinking rumination. Perspectives on Psychological Science, 3(5), 400-424. doi: 10.1111/j.1745-6924.2008.00088.x

Olson, M. L., \& Kwon, P. (2008). Brooding perfectionism: refining the roles of rumination and perfectionism in the etiology of depression. Cognitive Therapy and Research, 32(6), 788-802. doi: $10.1007 / \mathrm{s} 10608-007-9173-7$

Piñeiro, B., López-Durán, A., Martínez, Ú., Brandon, T. H., \& Becoña, E. (2014). Craving y abstinencia de la nicotina en fumadores españoles en un tratamiento para dejar de fumar [Craving and nicotine withdrawal in a Spanish smoking cessation sample]. Adicciones, 26(3), 230. doi: 10.20882/adicciones.4

Pomerleau, O., Pomerleau, C., Mehringer, A., Snedecor, S., Ninowski, R., \& Sen, A. (2005). Nicotine dependence, depression, and gender: Characterizing phenotypes based on withdrawal discomfort, response to smoking, and ability to abstain. Nicotine \& Tobacco Research, 7(1), 91-102. doi: $10.1080 / 14622200412331328466$

Preacher, K. J., \& Hayes, A. F. (2008). Asymptotic and resampling strategies for assessing and comparing indirect effects in multiple mediator models. Behavior Research Methods, 40(3), 879-891. doi: 10.3758/BRM.40.3.879

Preacher, K. J., \& Kelley, K. (2011). Effect size measures for mediation models: Quantitative strategies for communicating indirect effects. Psychological Methods, 16(2), 93-115. doi: 10.1037/a0022658

Querstret, D., \& Cropley, M. (2013). Assessing treatments used to reduce rumination and/or worry: a systematic review. Clinical Psychology Review, 33(8), 996-1009. doi: 10.1016/j.cpr.2013.08.004

Richmond, M., Spring, B., Sommerfeld, B. K., \& McChargue, D. (2001). Rumination and cigarette smoking: A bad combination for depressive outcomes? Journal of Consulting and Clinical Psychology, 69(5), 836-840. doi: 10.1037/0022-006X.69.5.836

Sanz, J., Perdigón, A. L., \& Vázquez, C. (2003). Adaptación española del Inventario para la Depresión de Beck-II (BDI-II): 2 . Propiedades psicométricas en población general. [The spanish adaptation of Beck's Depression Inventory-II ( BDI-II ): 2. Psychometric properties in the general population]. Clinica y Salud, 14(3), 249-280.

Sayette, M. A. (2016). The Role of Craving in Substance Use Disorders: Theoretical and Methodological Issues. Annual Review of Clinical Psychology, 12(1), 407-433. doi: 10.1146/annurev-clinpsy- 
021815-093351

Segal, Z. V., Williams, J. M. G., \& Teasdale, J. D. (2013). Mindfulness-based cognitive therapy for depression. New York, NY: Guilford Press.

Senra, C., Merino, H., \& Ferreiro, F. (2018). Exploring the link between perfectionism and depressive symptoms: Contribution of rumination and defense styles. Journal of Clinical Psychology, 74(6), 1053-1066. doi: 10.1002/jclp.22571

Skinner, M. D., \& Aubin, H. J. (2010, March). Craving's place in addiction theory: Contributions of the major models. Neuroscience and Biobehavioral Reviews, Vol. 34, pp. 606-623. doi: 10.1016/j.neubiorev.2009.11.024

Spada, M. M., Caselli, G., \& Wells, A. (2013). A Triphasic Metacognitive Formulation of Problem Drinking. Clinical Psychology \& Psychotherapy, 20(6), 494-500. doi: 10.1002/cpp.1791

Tiffany, S. T., \& Wray, J. M. (2012). The clinical significance of drug craving. Annals of the New York Academy of Sciences, 1248(1), 1-17. doi: 10.1111/j.1749-6632.2011.06298.x

Tjora, T., Hetland, J., Aar $\varnothing$, L. E., Wold, B., Wiium, N., \& Øverland, S. (2014). The association between smoking and depression from adolescence to adulthood. Addiction, 109(6), 1022-1030. doi: 10.1111/add.12522

Treynor, W., Gonzalez, R., \& Nolen-Hoeksema, S. (2003). Rumination reconsidered: a psychometric analysis. Cognitive Therapy and Research, 27(3), 247-259. doi: 10.1023/A:1023910315561

Ussher, M., Beard, E., Abikoye, G., Hajek, P., \& West, R. (2013). Urge to smoke over 52 weeks of abstinence. Psychopharmacology, 226(1), 83-89. doi: 10.1007/s00213-012-2886-7

Watkins, E. R. (2008). Constructive and unconstructive repetitive thought. Psychological Bulletin, 134(2), 163-206. doi: 10.1037/0033-2909.134.2.163

Weinberger, A. H., George, T. P., \& McKee, S. A. (2011). Differences in smoking expectancies in smokers with and without a history of major depression. Addictive Behaviors, 36(4), 434-437. doi: 10.1016/J.ADDBEH.2010.12.024

Weinberger, A. H., Kashan, R. S., Shpigel, D. M., Esan, H., Taha, F., Lee, C. J., ... Goodwin, R. D. (2016). Depression and cigarette smoking behavior: A critical review of population-based studies. The American Journal of Drug and Alcohol Abuse, 43(4), 416-431. doi: 10.3109/00952990.2016.1171327

Weinberger, A. H., Pilver, C. E., Desai, R. A., Mazure, C. M., \& McKee, S. A. (2013). The relationship of dysthymia, minor depression, and gender to changes in smoking for current and former smokers: Longitudinal evaluation in the U.S. population. Drug and Alcohol Dependence, 127(1-3), 170-176. doi: 10.1016/j.drugalcdep.2012.06.028

Whisman, M. A., du Pont, A., \& Butterworth, P. (2020). Longitudinal associations between rumination 
and depressive symptoms in a probability sample of adults. Journal of Affective Disorders, 260, 680-686. doi: 10.1016/j.jad.2019.09.035

Willem, L., Bijttebier, P., Claes, L., \& Raes, F. (2011). Rumination subtypes in relation to problematic substance use in adolescence. Personality and Individual Differences, 50(5), 695-699. doi: 10.1016/J.PAID.2010.12.020

Wray, J. M., Gass, J. C., \& Tiffany, S. T. (2013). A systematic review of the relationships between craving and smoking cessation. Nicotine and Tobacco Research, 15(7), 1167-1182. doi: $10.1093 / \mathrm{ntr} / \mathrm{nts} 268$

Ziedonis, D., Hitsman, B., Beckham, J. C., Zvolensky, M., Adler, L. E., Audrain-McGovern, J., ... Riley, W. T. (2008). Tobacco use and cessation in psychiatric disorders: National Institute of Mental Health report. Nicotine \& Tobacco Research, 10(12), 1691-1715. doi:

$10.1080 / 14622200802443569$ 
Table 1

Descriptive statistics and bivariate correlations

\begin{tabular}{|c|c|c|c|c|c|c|}
\hline & $\operatorname{Mean}(S D)$ & 1 & 2 & 3 & 4 & 5 \\
\hline 1. BDI-II & $10.46(9.14)$ & - & & & & \\
\hline 2. Brooding & $4.59(3.26)$ & $.55^{* * *}$ & - & & & \\
\hline 3. Reflection & $4.10(3.24)$ & $.31^{* * *}$ & $.60^{* * * *}$ & - & & \\
\hline 4. FTCD & $4.78(2.16)$ & $.24^{* * *}$ & $.23^{* * *}$ & $.17^{* *}$ & - & \\
\hline 5. Craving $^{1}$ & $2.97(0.99)$ & $.21^{* * * *}$ & $.29^{* * *}$ & $.22^{* * *}$ & $.30^{* * *}$ & - \\
\hline
\end{tabular}

${ }^{1}$ MNWS item 8

Note. BDI-II: Beck Depression Inventory-II; FTCD: Fagerström Test of Cigarette Dependence; MNWS: Minnesota Nicotine Withdrawal Scale ${ }^{*} p<.05 ;{ }^{* *} p<.01 ;{ }^{* * *} p<.001$. 
Table 2

Results of multiple mediation analysis of the relation between depressive symptoms and cigarette dependence and withdrawal symptoms $(n=275)$

\begin{tabular}{|c|c|c|c|c|c|}
\hline & $\boldsymbol{\beta}$ & SE & $p$ & LLCI & ULCI \\
\hline Outcome: FTND & Direct & & & & \\
\hline BDI-II & .162 & .016 & .021 & .005 & .071 \\
\hline Brooding & .116 & .051 & .170 & -.033 & .186 \\
\hline Reflection & .086 & .048 & .239 & -.038 & .153 \\
\hline Sex & -.127 & .265 & .034 & -1.088 & -.041 \\
\hline Age & .089 & .011 & .126 & -.005 & .040 \\
\hline \multicolumn{6}{|c|}{ Indirect } \\
\hline Brooding & .063 & .011 & & -.007 & .036 \\
\hline Reflection & .025 & .005 & & -.004 & .018 \\
\hline Total indirect effect & .089 & .009 & & .017 & .040 \\
\hline \multicolumn{6}{|c|}{ Contrasts } \\
\hline Brooding vs. reflection & .009 & .014 & & -.020 & .037 \\
\hline Outcome: Craving ${ }^{1}$ & Direct & & & & \\
\hline BDI-II & .199 & .006 & $<.001$ & .009 & .023 \\
\hline Brooding & .186 & .025 & .028 & .006 & .107 \\
\hline Reflection & .071 & .022 & .328 & -.022 & .066 \\
\hline Sex & .077 & .122 & .197 & -.083 & .399 \\
\hline Age & .009 & .005 & .869 & -.009 & .011 \\
\hline \multicolumn{6}{|c|}{ Indirect } \\
\hline Brooding & .101 & .041 & & .023 & .186 \\
\hline Reflection & .021 & .020 & & -.019 & .063 \\
\hline Total indirect effect & .123 & .040 & & .048 & .205 \\
\hline \multicolumn{6}{|c|}{ Contrasts } \\
\hline Brooding vs. reflection & -.080 & .052 & & -.019 & .184 \\
\hline
\end{tabular}

${ }^{1}$ MNWS item 8

Note: $\mathrm{SE}=$ Standard Error; $\mathrm{LLCI}=$ lower limit confidence interval; ULCI = upper limit confidence interval. Standardized regression coefficients are presented 


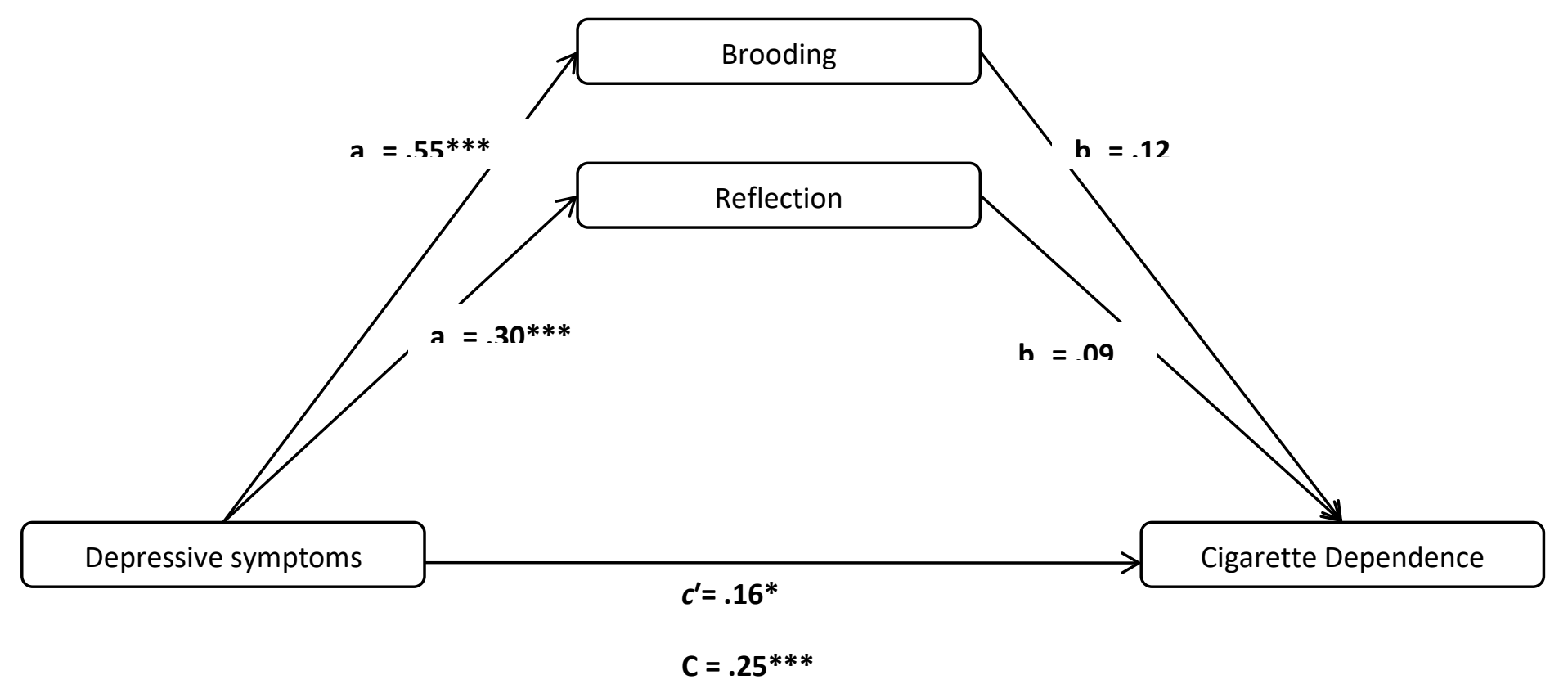

\section{Fig. 1}

Illustration of the multiple mediational model for cigarette dependence Note: $a_{1}=$ Direct effect of depressive symptoms on brooding; $a_{2}=$ Direct effect of depressive symptoms on reflection; $b_{1}=$ direct effect of brooding on cigarette dependence; $b_{2}$ =direct effect of reflection on cigarette dependence; $c^{\prime}=$ direct effect of depressive symptoms on cigarette dependence accounting for mediators (brooding and reflection). $C=$ effect of depressive symptoms on cigarette dependence without accounting for mediators (brooding and reflection). Standardized regression coefficients from mediation analyses presented.

${ }^{*} p<0.05 .{ }^{* *} p<0.01 .^{* * *} p<0.001$. 


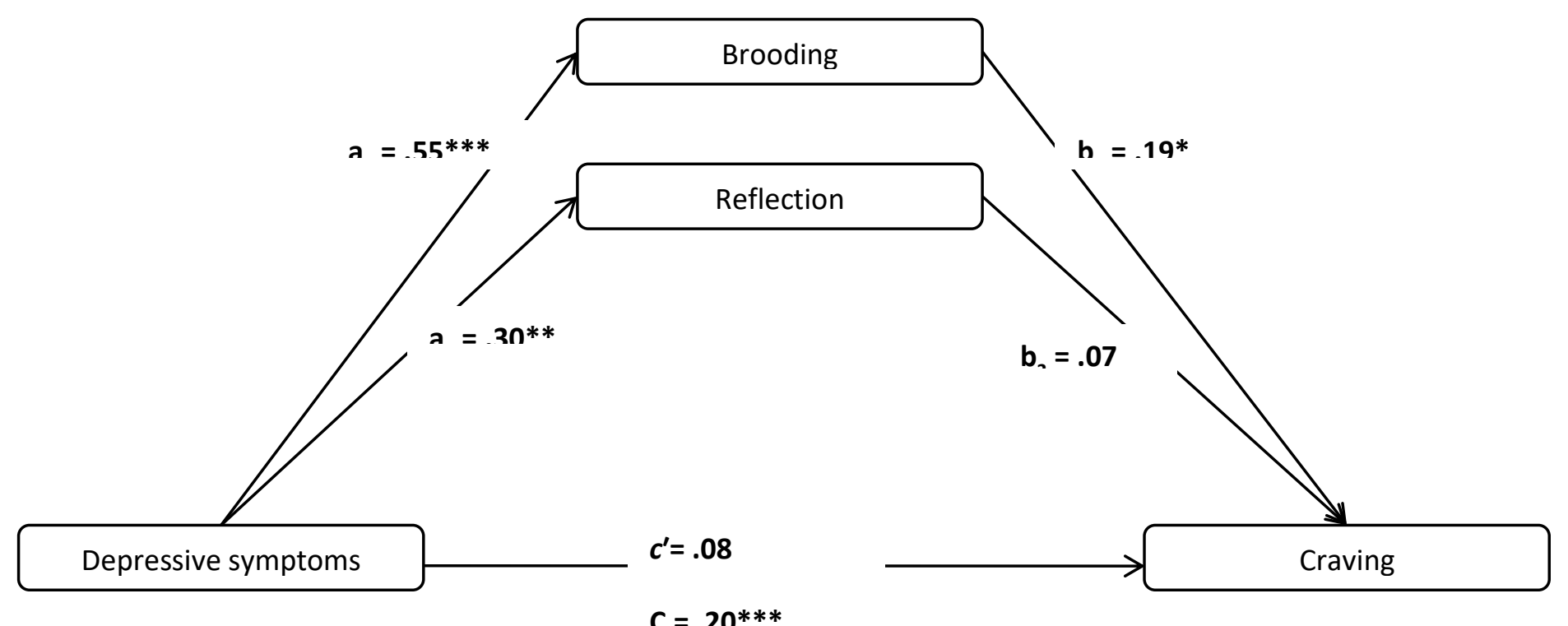

\section{Fig. 2}

Illustration of the multiple mediational model for tobacco craving

Note: $a_{1}=$ Direct effect of depressive symptoms on brooding; $a_{2}=$ Direct effect of depressive symptoms on reflection; $b_{1}=$ direct effect of brooding on craving; $b_{2}=$ direct effect of reflection on craving; $c^{\prime}=$ direct effect of depressive symptoms on craving accounting for mediators (brooding and reflection). $\mathrm{C}$ = effect of depressive symptoms on craving without accounting for mediators (brooding and reflection). Standardized regression coefficients from mediation analyses presented.

${ }^{*} p<0.05 .^{* *} p<0.01 .^{* * *} p<0.001$. 